\title{
THE EFFECT OF EDUCATION ON PARENTS' "SPEAK UP" KNOWLEDGE REGARDING PATIENTS SAFETY IN HOSPITAL
}

\author{
Septy Nur Aini*, Sri Mulatsih**, Patricia Suti Lasmani*** \\ *Magister of Nursing, Faculty of Medicine, Universitas Gadjah Mada \\ **Pediatric Department RSUP Dr. Sardjito Yogyakarta \\ ***Pediatric Intensive Care Unit RSUP Dr. Sardjito Yogyakarta \\ E-mail: ainis_sky@yahoo.com
}

\begin{abstract}
Introduction: Safety is a global issue in hospitals. Unexpected events or errors related to health services occur in children, and about $75 \%$ are associated with medical procedures. Parental involvement becomes one of the strategies used to improve patient safety. Families who know patient safety can educate themselves to prevent and detect errors that occur during treatment. Education can improve the general knowledge about patient safety. The Speak Up program is recommended by JCAHO to improve effective communication, and this program has a preventive impact on human error. This study aims to determine the effect of education on parent's 'speaking up' knowledge regarding patient safety in the Children's Wards of Dr. Sardjito Hospital in Yogyakarta. Methods: This research study was quasi-experimental using a one group pre-test and posttest design. The intervention in this research was education. The consecutive sampling technique was used with a total of 62 respondents selected. The Speak Up questionnaire and observation sheet to get to know the changes in the knowledge of Speak Up was used to collect the data. The data analysis used a Paired Sample T-Test. Result: The result of the paired T-test showed a p-value $<0,001(\mathrm{p}<0,05)$ which means that there was a significant influence by way of education on parent's speak up knowledge regarding patient safety. Conclusion: Education improved the parents' speak up knowledge about patient safety.
\end{abstract}

Keywords: Education, Patient Safety, Speak up

\section{INTRODUCTION}

Patient safety strategies are designed to avoid, prevent and minimise unexpected events as a result of healthcare practices. The definition of patient safety is to reduce the risk of unnecessary actions to a minimum level in the provision of health services (WHO, 2009; Runciman et al., 2009).

Safety is a global issue in hospitals. In developing countries, one in ten patients is estimated to be injured during hospitalisation. Every 100 patients, approximately seven in developed countries and ten in developing countries, have infections related to health services (WHO, 2015). Based on the reports of patient safety incidents in January to April 2010, the West Java Province ranks first for adverse events $(33,33 \%)$, followed by Banten and Central Java (20\%), and then DKI Jakarta $(16,67 \%)$, Bali $(6,67 \%)$, and East Java $(3,33 \%)$. Adverse events are caused by issues with procedures, documentation, and medications (KKPRS, 2010). Errors associated with health services also occur in children. Children are very vulnerable to medical errors as they are totally dependent on the communication and the other behaviours of adults in preventing the occurrence of errors (Cox et al., 2012). In addition to vulnerability, as children are in a stage of growth and development, they require special attention when it comes to their safety (Schatkoski et al., 2009).

Parental involvement in improving patient safety is one of the strategies that need to be undertaken to support the quality and safe environments in health care organisations (Schatkoski et al., 2009; American Academy of Pediatrics, 2012). This level of parental involvement has a positive impact on the quality of the health services, patient and family satisfaction and cost-effectiveness (American Academy of Pediatrics, 2012). According to Ottosen (2015), parents want to be involved as a partner in improving their child's safety in the hospital.

Related to these strategies, the Joint Commission Accreditation of Health Organization (JCAHO) recommended speak up as a method that can be used to improve the channels of communication between the health workers with patients and families in achieving patient safety goals. JCAHO launched the Speak Up ${ }^{T M}$ Patient Safety Program in 2002. The program has been used in more than 40 countries (The Joint Commission, 2015).

In a survey conducted by The Joint Commission regarding the Speak $U p^{T M}$ Patient Safety Program, it found that $83 \%$ of respondents stated that speak up encourages and educates patients and includes them as being partners in their care. $83 \%$ of respondents believed that speak up was easy to 
use, and $83 \%$ of the respondents also believed that speak up carried value for the healthcare organizations. $69 \%$ of respondents would recommend the program to their colleagues, friends, family members or patients. The Speak $U p^{T M}$ Patient Safety Program can be used not only by the patients themselves but also by their families (The Joint Commission, 2015).

The involvement of patients and their families in improving patient safety is influenced by autonomy, awareness, and knowledge (Buetow et al., 2013). Longtin et al. (2010) suggested that patients and their families with safety knowledge can educate themselves in order to prevent human errors by the health workers while detecting errors occurring during care in the preparation, monitoring, and follow-up of an action.

Abdi et al. (2012) argued that education increases knowledge, attitudes, and behaviour about patient safety. In some studies,it was also reported that speak up behaviour increased after interventions (Sayre et al., 2012; Johnson and Kimsey, 2012). Hesitation in speak up is an important factor in communication errors. Hence there needs to be training as an effective way of improving speak up behaviour (Okuyama et al., 2014).

\section{MATERIALS AND METHODS}

The research was a quasi-experiment with a one group pre-test and post-test design to determine the effect of education on parent's knowledge of Speak Up in relation to patient safety. The study was conducted in the Children's Wards of one of the public hospitals in Yogyakarta from October 2016 until March 2017. The participants in this study were parents with children being treated in the Children's Wards. Samples were taken using the consecutive sampling technique with a total of 62 respondents.

The independent variable was education while the dependent variable was Speak Upknowledge about patient safety. The Speak up knowledge questionnaire and the Speak Up observation sheet were used to collecting the data. Data analysis using Paired Sample T-Test with a significance value of $\alpha=$ 0,05 and $\mathrm{CI}=95 \%$ was used. The study was approved according to the protection of human rights and welfare in the medical research division by the Ethical Committee of the Faculty of Medicine at the Universitas Gadjah Mada, Yogyakarta. The research flow of the study can be seen in Figure 1.

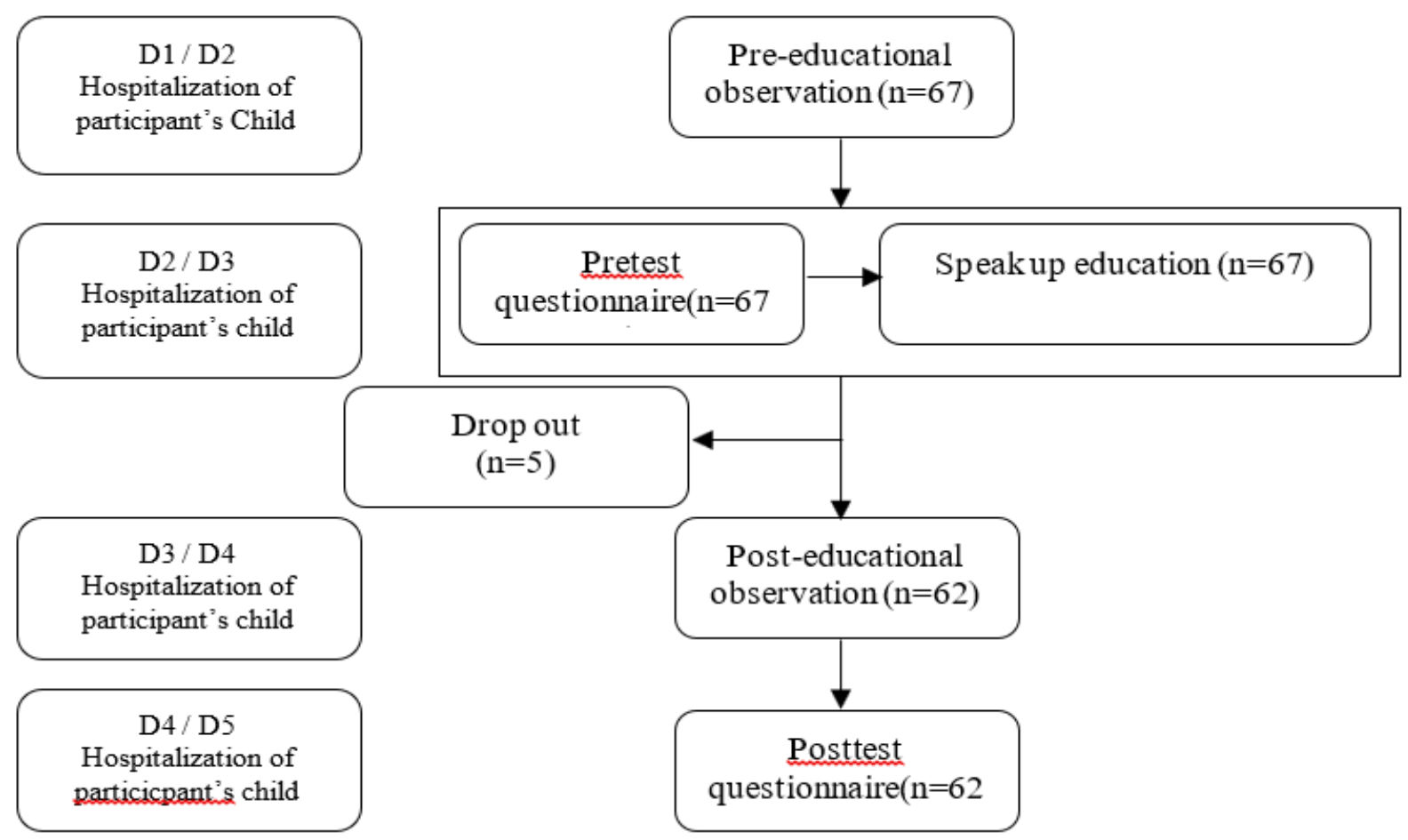

Figure 1. The flow of the research 


\section{RESULTS}

The demographic characteristics of the 62 participants included age, gender, education,occupation and their previous knowledge about Speak Up. Most of the participants were aged 31-40 years old $(43,5 \%)$. More than two thirds $(77,4 \%)$ of the participants were female, and almost half of them $(41,9 \%)$ were high school graduates. More than half of the participants $(59,7 \%)$ worked as a housewife. The majority of the participants $(91,9 \%)$ had never heard of the Speak Up program.

Table 1 showed that the mean of the parents' Speak Up knowledge increased after the intervention with the highest mean being in relation to the prevention of infection by hand washing. The means of the parent's Speak Up knowledge increased except in the following areas of care advocacy (advisor/supporter), medicine explanation, insertion area infection, hospital accreditation and the health personnel who are in charge of the care.

The differences in the parents' Speak Up knowledge about patient safety pre- and post-education are shown in Table 2 . The means of Speak Up knowledge about patient safety was decreased in 8 participants and increased in 44 participants. The paired T-test results showed significance at $p<0,001$. The $\mathrm{p}<0,05$ and CI scores did not pass through zero which showed significant mean differences in the parents' Speak Up knowledge about patient safety pre- and post-education (see Table 2).

Table 1. Means of parent's speak up knowledge about patient safety in Children's Wards of Dr. Sardjito Hospital Yogyakarta $(n=62)$

\begin{tabular}{|c|c|c|}
\hline Speak Up about patient safety items & $\begin{array}{l}\text { Knowledge pre } \\
\text { education }\end{array}$ & $\begin{array}{l}\text { Knowledge post } \\
\text { education } \\
\text { Mean (Std. Dev.) }\end{array}$ \\
\hline $\begin{array}{l}\text { Definition of speak up about patient safety } \\
\text { Item 1. Definition of patient safety }\end{array}$ & $0,9032( \pm 0,29806)$ & $0,9516( \pm 0,21633)$ \\
\hline $\begin{array}{l}\text { Speak up if you have questions or concerns } \\
\text { Item 2. Use translator }\end{array}$ & $0,5323( \pm 0,50303)$ & $0,7258( \pm 0,44975)$ \\
\hline $\begin{array}{l}\text { Pay attention to the care your children get } \\
\text { Item } 3 \text {. Infection prevention by washing hands } \\
\text { Item } 4 \text {. How to do the patient identification } \\
\text { Item 5. The time to do patient identification }\end{array}$ & $\begin{array}{l}0,3226( \pm 0,47128) \\
0,5806( \pm 0,49748) \\
0,5968( \pm 0,49455)\end{array}$ & $\begin{array}{l}0,6774( \pm 0,47128) \\
0,8710( \pm 0,33747) \\
0,7258( \pm 0,44975)\end{array}$ \\
\hline $\begin{array}{l}\text { Educate yourself and children about the illness } \\
\text { Item } 6 \text {. The source of information } \\
\text { Item } 7 \text {. Information recording }\end{array}$ & $\begin{array}{c}1(0) \\
0,4677( \pm 0,50303)\end{array}$ & $\begin{array}{c}1(0) \\
0,7903( \pm 0,41040)\end{array}$ \\
\hline $\begin{array}{l}\text { Ask your trusted family member or friend to be } \\
\text { advocate on your children care } \\
\text { Item } 8 \text {. Advocate task } \\
\text { Item } 9 \text {. Advocate personnel }\end{array}$ & $\begin{array}{l}0,8871( \pm 0,31906) \\
0,4194( \pm 0,49748)\end{array}$ & $\begin{array}{l}0,7581( \pm 0,43175) \\
0,7581( \pm 0,43175)\end{array}$ \\
\hline $\begin{array}{l}\text { Know what medicines your children take and } \\
\text { why it is taken } \\
\text { Item } 10 . \text { Medicines explanation } \\
\text { Item } 11 . \text { The insertion area infection report }\end{array}$ & $\begin{array}{c}0,9677( \pm 0,17813) \\
1(0)\end{array}$ & $\begin{array}{c}0,9516( \pm 21633) \\
0,9839( \pm 0,127)\end{array}$ \\
\hline $\begin{array}{l}\text { Use a health care organization that has been } \\
\text { carefully checked out } \\
\text { Item } 12 \text {. Hospital selection } \\
\text { Item } 13 \text {. Hospital accreditation }\end{array}$ & $\begin{array}{l}0,9677( \pm 0,17813) \\
0,6613( \pm 0,47713)\end{array}$ & $\begin{array}{c}1(0) \\
0,6452( \pm 48237)\end{array}$ \\
\hline $\begin{array}{l}\text { Participate in all decisions about your children } \\
\text { treatment } \\
\text { Item } 14 \text {. Family role } \\
\text { Item } 15 \text {. Health personnel in charge of the care }\end{array}$ & $\begin{array}{l}0,4355( \pm 0,49987) \\
0,0645( \pm 0,24768)\end{array}$ & $\begin{array}{c}0,5161( \pm 0,50382) \\
0,484( \pm 0,21633)\end{array}$ \\
\hline
\end{tabular}


Table 2. Paired T-test results on parent's Speak up knowledge about patient safety pre and post education $(\mathrm{n}=62)$

\begin{tabular}{lllll}
\hline & Mean & Deviation & CI95\% & P value \\
\hline $\begin{array}{l}\text { Speak up knowledge pre } \\
\text { intervention(n=62) }\end{array}$ & $9,81( \pm 1,62)$ & $1,6(2,0)$ & $1,09-2,11$ & $<0,001$
\end{tabular}

Speak up knowledge post $\quad 11,40( \pm 1,82)$

intervention $(n=62)$

\section{DISCUSSION}

The study was conducted for six months from October 2016 to March 2017 in the Children's Wards of one public hospital in Yogyakarta. The study was conducted in the Yogyakarta Hospital as it is an accredited hospital (Joint Commission International Accreditation) where one of the accreditation assessments is related to patient safety.

The patient's involvement through support for Speak Up is a way of reducing unexpected events and will increase the outcome of patient safety (Saufi, 2003). The recognition and support towards Speak Up for health professionals as well as from the patients and their families is a form of transformation to improve the patient's safety culture in relation to health care (Donnelly et al. 2010; Blanco et al., 2009; Spruce, 2014). Research on communication in healthcare has been conducted because it significantly contributes towards the outcomes of unexpected events (Pierce, 2016).

The study showed that the means of the parent's Speak Up knowledge is higher on the definition of patient safety, drug explanations, reporting insertion area infection, and hospital selection items. There is an increase in knowledge after education on the patient's safety definition, the use of a translator, infection prevention, patient identification, information recording, care advocating, hospital selection and the health care personnel in charge.

The parents' Speak Up knowledge had the highest increasing means after education on infection prevention by hand washing. In the provision of new patient information, one of the information materials is an explanation of how to handwash correctly. The family are taught the purpose and the technique of hand washing. The new patient information was given for a limited time and included a considerable amount of material. During the parents' Speak Up education about patient safety, the parents were educated on the importance of handwashing and to remind the healthcare personnel to wash their hands as a way to prevent infections in their children.

The education is conducted as a way to provide information and to examine the influence on the parent's Speak Up knowledge about patient safety. The study showed that education has a significant influence on improving the parent's Speak Up knowledge about patient safety.

The result of this study is supported by the research conducted by O'Connor et al. (2013) on interns about the effect of Speak Up training. In that study, the knowledge increased significantly, and there was a change in the attitude of the interns. However, the training did not affect the behaviour of the trainee to speak up about patient safety. Sayre et al. (2012) stated that the educational intervention improved the behaviour of 'speaking up'in the nurses and increased their score of speaking up. Lawrence et al. (2011) showed that the parent's knowledge increased after being given education using a booklet as the information source. The advantage of using a booklet as the information source was the influence on learning memories as this method can be read over repeatedly (Arsyad, 2010).

Barzallo et al. (2014) did a study on the surgeon's Speak Up training.The motivation to Speak Up about patient safety was performed by $82 \%$ of surgeons in a Speak Up support group where $30 \%$ in the group were not provided support to Speak Up. The increasing use of Speak Up knowledge cannot be separated from the support of the healthcare personnel.

Many factors influence Speak Up. For patients and families, Speak Up is influenced by the ability to recognise changes in clinical conditions, confidence, trustworthiness, culture and the health care systems (Rainey et al., 2013). There is two main factors affecting Speak Up; personal and health care organisation (Lyndon et al., 2015). According 
to Rainer (2015), Okuyama et al. (2014), and Garon (2012), personal factors that can affect Speak Up include communication skills and educational background. The current study showed that the parent's educational background is dominated by a high school education level. Approximately $70 \%$ of parent's education of high school or below. These results need to be followed by further research to know better about the influence of educational background towards Speak Up knowledge.

The results of the pre- and posteducational observations indicate that education cannot be attributed to Speak Up actions in isolation. Law and Chan (2015) suggested that learning to Speak Up requires more than one occurrence of training. Mentoring in the education process is needed to create a safer environment (Law and Chan, 2015).

Hrisos and Thomson (2013) stated that sometimes patients and families are afraid to Speak Up because it may be considered rude and shows no respect towards the healthcare personnel. Patients and their families found that they could comfortably Speak Up with healthcare personnel who were better known than other professionals whom they had just met. Obstacles to Speak Up can include the presence of others, knowledge, limited time and fear of speak (Schwappach \& Gehring, 2014). The parents found that advice directed to the healthcare personnel can be a problem because it is considered as being a form of distrust between the patients and healthcare personnel where the patients or families do not want it to happen (Peat et al., 2010). Goelts and Hatlie (2002), cited in Peat et al. (2010) suggested that asking whether the health care personnel were washing their hands or not was a form of Speak Up that should be conducted by the patients and their families. However, they chose not to ask the question. The parents tended to choose silence and did not ask, implying lack of trust to cause them to avoid mentioning any problems with health care personnel (Peat et al., 2010).

Nacioglu (2016) and Garon (2012) stated that one of the factors that affect Speak Up is cultural background. Qingzue (2003) and Claramita et al. (2013) reported that communication was strongly related to cultural characteristics. Indonesia, as an Eastern country, has a different style of communication from Western countries. Communication for Asian people is more often indirect and implicit, in contrast to Western culture which is known for being assertive, with aggressive communication behaviours (Claramita et al., 2013).

\section{CONCLUSIONS}

Educational interventions influenced the parents' Speak Up knowledge to do with patient safety. There is an increase in knowledge after education on patient safety has been provided.

Parents need to be educated continuously on Speak Up about patient safety. Further research is required regarding the implementation of patient safety by nurses, the factors influencing the implementation of the parents' Speak Up about patient safety and the effect of education on speaking up using a control group.

\section{REFERENCES}

Abdi, Z., Delgoshaei, B., Ravaghi, H., Heyrani, A. (2012). Changing Medical Student's Knowledge, Skills, and Attitudes About Patient Safety. HealthMED, Volume 6, Number 9

American Academy of Pediatrics.(2011). Policy Statement: Patient and FamilyCentred Care and Pediatrician's Role. Retrieved January 17, 2016, from http://www.pediatrics.org/cgi/doi/10.1 542/peds.2011-3084

Arsyad, Azhari. (2010). Media Pembelajaran. Jakarta: PT Raja GrafindoPersada

Barzallo S.M.J., Minkoff H., Bayya J., Gillett B., Onoriode H., Weedon J., Altshuler L., Fisher N. (2014). Influence of Surgeon Behavior on Trainee Willingness to Speak Up: A Randomized Control Trial. Journal of the American College of Surgeons. Nov, 219(5):1001-7. doi: 10.1016/j.jamcoolsurg.2014.07.933

Blanco, M., Clarke JR., Martindeli D. (2009). Wrong Site Surgery Near Misses and Actual Occurrences. Association of peri-Operative Registered Nurses Journal. ;90(2):215-8,221-2. doi: 10.1016/j.aorn.2009.07.010

Buetow, S., Davis R., Callaghan K., Dovey S.(2013). What Attributes of Patient Affect Their Involvement in Safety? A 
Key Opinion Leaders Perspective. British Medical Journal Open;3:e003104. doi: 10.1136/bmjopen-2013-003104

Claramita, M., Mubarika D.F., Nugraheni, van Dalen, J., van der Vleuten, C.(2013). Doctor-Patient Communication in Southeast Asia: a Different Culture? Advance in Health Sciences Education; $\quad 18: 15-31$. doi:10.1007/s10459-012-9352-5

Cox, E.D., Carayon, P., Hansen, K.W., Rajamanickam, V.P., Brown, R.L., Rathouz, P.J., et al. (2012). Parent Perception of Children's Hospital Safety Climate. British Medical Journal Quality and Safety; 22(8):664671. doi: 10.1136/bmjqs-2012-001727

Donelly, FL., Dickerson MJ, Goodfriend AM., Muething ES. (2010). Improving Patient Safety in Radiology: Concepts for a Comprehensive Patient Safety Program. American journal of Roentgenology;194(5):1183-7. doi: 10.2214/AJR.09.3875

Garon M.(2012). Speaking Up, Being Heard: Registered Nurses Perceptions of Workplace Communication. Journal of Nursing Management; 20(3):36171.doi: $10.1111 / \mathrm{j} .1365-$ 2834.2011.01296.x.

Hrisos, S., Thomson, R. (2013). Seeing It from Both Sides: Do Approaches to Involving Patients in Improving Their Safety Risk Damaging the Trust between Patient and Healthcare Professionals? An Interview Study. PloS ONE 8(11): e80759. doi:10.1371/journal.pone.0080759

Johnson, HL., Kimsey, D. (2012). Patient safety: Break the Silence. Association of peri-Operative Registered Nurses Journal, 95(5):591-601. doi: 10.1016/j.aorn.2012.03.002

KKPRS. (2010). Laporan Insiden Keselamatan Pasien. Retrieved January 10, 2015, from www.inapatsafetypersi.or.id/umpan_balik/laporan_ikp2. pdf

Law, Y.B., Chan, A.E. (2015). The Experience of Learning to Speak Up: a Narrative Inquiry on Newly Graduated Registered Nurses. Journal of Clinical
Nursing;24(13-14): 1837-48. doi: 10.1111/jocn. 12805

Lawrence, KS., Stilley CS, Pollock JA, Webber SA, Quivers ES. (2011). A Family-Centred Educational Program to Promote Independence in Pediatric Heart Transplant Recipients. Progress in Transplantation; 21(1):61-6

Longtin, Y., Sax, H., Leape, L.L., Sheridan, S.E., Donaldson, L., Pittet, D. (2010). Patient Participation: Current Knowledge and Applicability to Patient Safety. Mayo ClinicProceedings;85(1):53-62. doi: 10.4065/mcp.2009.0248

Lyndon, A., Johnson MC., Bingham D., Napolitani PG., Joseph G., Maxfield DG., O'Keeffle DF. (2015). Transforming Communication and Safety Culture in Intrapartum Care: a Multi-Organization Blueprint. Journal of Obstetric,Gynecologic\& Neonatal Nursing; 44(3):341-9. doi: $10.1111 / 1552-6909.12575$

Nacioglu, Ahmet. (2016). As a Critical Behavior to Improve Quality and Patient Safety in Health Care: Speaking Up!. Safety in Health (2016) 2:10. doi: 10.1186/s40886-016-0021-x

O'Connor, P., Byrne D, O'Dea A., McVeigh TP., Kerin MJ. (2013). "Excuse Me" Teaching Intern to Speak Up. The Joint CommissionJournal onQuality and Patient Safety; 39(9): 426-31. doi: 10.1016/S1553-7250(13)39056-4

Okuyama, A., Wagner, C., Bijnen, B. (2014). Speaking Up for Patient Safety by Hospital-based Health care Professionals: A Literature Review. BioMedCentral Health Service Research, 14:61. doi: 10.1186/14726963-14-61

Ottosen, M.J. (2015). Parent Perceptions of Patient Safety Culture in the Neonatal Intensive Care Unit. UT SON Dissertation. Texas Medical Center Library

Peat, M., Entwistle, V., Hall, J., Birks, Y., Golder, S. (2010). Scoping Review and Approach to Appraisal of Interventions Intended to Involve Patients in Patient Safety. Journal of Health Services Research \& Policy, Vol 15 Suppl 1. doi: 10.1258/jhsrp.2009.009040 
Pierce, BR. (2016). Speaking Up: It Requires Leadership Maturity. Nurse Leader; 14(6):413-418. doi: 10.1016/j.mnl.2016.08.005

Rainer, J. (2015). Speaking Up: Factors and Issues in Nurses Advocating for Patients When Patients are in Jeopardy. Journal of Nursing Care Quality; 30(1):53-62. doi: 10.1097/NCQ.0000000000000081

Rainey, H., K. Enrich, N. Mackintosh, J. Sandall. (2013). The Role of Patient and Their Relatives in 'Speaking Up' About Their Own Safety - a Qualitative Study of Acute Illness. Health Expectation, 18, pp.392-405. doi:10.1111/hex.12044

Runciman, W., Hibbert, P., Thomson, R., van der Scaaf, T., Sherman, H., Lewalle, P. (2009). Towards an International Classification for Patient Safety: Key Concepts and Terms. International Journal for Quality in Health Care;21(1):18-26. doi: 1.1093/infqhe/mzn057

Saufi, N.M. (2003). Patient Encouraged to "Speak Up". Retrieved April 4, 2016, from http://ac.elscdn.com.eproxy1.lib.hku.hk/S1089947 203000054/1-s2.0-

S108947203000054main.pdf?_tid=339caeb8-a6e5-11e5b6c000000aab0f27\&acdnat $=1450594085$ daf5fe7b7d3660645b216bf2d8000b

Sayre, M.M., McNeese-Smith, D., Leach, LS., Phillips, LR. (2012). An Educational Intervention to Increase "Speaking-
Up" Behaviors in Nurses and Improve Patient Safety. Journal of Nursing Care Quality, 27(2):154-60.doi: 10.1097/NCQ.0b013e318241d9ff.

Schatkoski, A.M., Wegner, W., Algeri, S., Pedro, E.N.R. (2009). Safety and Protection for Hospitalized Children: Literature Review. Revista LatinoAmericana deEnfermagem; 17(3):410$6 . \quad$ doi: $10.1590 / \mathrm{S} 0104-$ 11692009000300020

Schwappach, DL., Gehring K. (2014). Tradeoffs, Between Voice and Silence: A Qualitative Exploration of Oncology Staff's Decision to Speak Up About Safety Concern. BioMed Central of Health Service Research. 14;14:303. doi: 10.1186/1472-6963-14-303

Spruce, L. (2014). Back to Basics: Preventing Surgical Site Infections. Association of peri-Operative Registered Nurses Journal; 99(5):600-8. doi: 10.1016/j.aorn.2014.02.002

The Joint Commission. (2015). Facts About Speak Up. Retrieved November 15, 2015, from http://www.jointcommission.org/facts _about_speak_up/

WHO. (2009). A World Alliance for Safer Health Care. More Than Words: Conceptual Framework for the International Classification for Patient Safety. Version 1.1. Final Technical Report. Geneva: WHO (2015). Patient Safety. Retrieved April 23, 2015, from http://www.who.int/patientsafety/en/ 